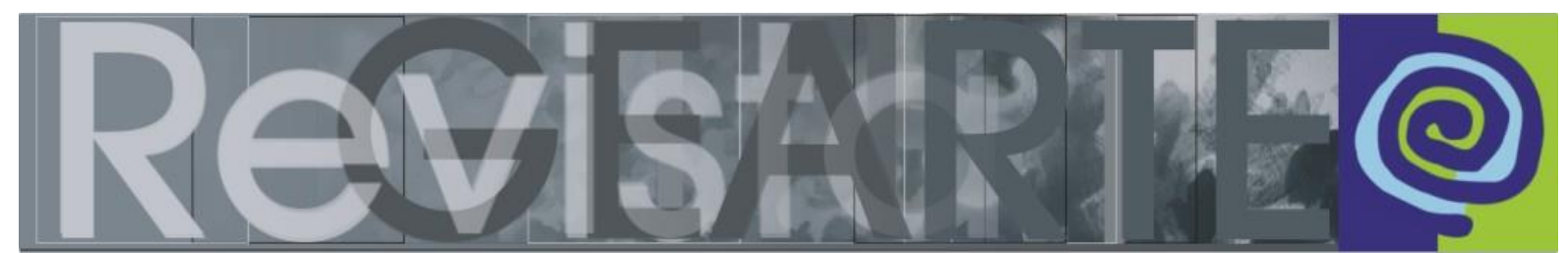

ISSN 2357-9854 | e-ISSN 2596-3198 (online)

\title{
Ensino de Artes Visuais: histórias e memórias
}

Quando foi feito o primeiro desenho na parede da caverna, foi proferido um mundo a pintar, o qual os pintores não fizeram senão retomar e reabrir Quando foi proferido o primeiro canto e o primeiro poema, foi prometido um mundo a cantar e a dizer que músicos e poetas não fizeram senão retomar e reabrir. Quando foi feito o primeiro gesto cerimonial, foi prometido um mundo a dançar e a esculpir que dançarinos e escultures não fizeram senão retomar e reabrir. Quando o primeiro pensamento foi expresso, foi prometido um mundo a pensar que filósofos e cientistas não fizeram senão retomar e reabrir.

A história como esquecimento, historicidade da morte, toma a obra acabada como prodígio a ser contemplado - é a história vista pelo mero espectador. A história como forma nobre da memória, historicidade da vida, é a que capta as obras como excesso do que se queria fazer, dizer e pensar, excesso que abre aos outros a possibilidade da retomada e da criação como carência e vazio no interior do excesso - é a história efetuada pelo trabalho dos artistas, escritores e pensadores. Inquietação instituinte sempre aberta.

Promessa de acontecimentos, instituição de adventos: todos esses termos exprimem a mesma significação, qual seja, o excesso do sentido sobre o sentido já realizado, fazendo com que arte, literatura e filosofia sejam sempre elucidação de uma percepção histórica aberta sobre o enigma de uma plenitude excessiva e carente. Por isso mesmo, diz Merleau-Ponty, a grandeza de uma obra não se mede por sua eficácia, e sim por sua fecundidade (CHAUI, 2010, p. 286-287).

\section{Retomar, reabrir...}

A compreensão da história como promessa de acontecimentos historicidade da vida - exige o gesto de "retomar e reabrir", pois tais gestos geram interpretações sobre o passado e nos ajudam a estabelecer relações com o nosso presente, por isso não despreza a memória. Pelo contrário, busca criar uma profunda articulação dialogal entre a história e a memória.

A escolha do tema, portanto, história e memória da arte/educação toma como sustentação filosófica o pensamento de Ana Mae Barbosa em relação à história e o pensamento de Ecléa Bosi (1994) em relação à memória. Sobre a memória, Bosi (1994, p. 81) chama a atenção:

\footnotetext{
Uma lembrança é diamante bruto que precisa ser lapidado pelo espírito. Sem o trabalho da reflexão e da localização, seria uma imagem fugidia. O sentimento também precisa acompanhá-la para que ela não seja uma repetição do estado antigo, mas uma reaparição.
} 


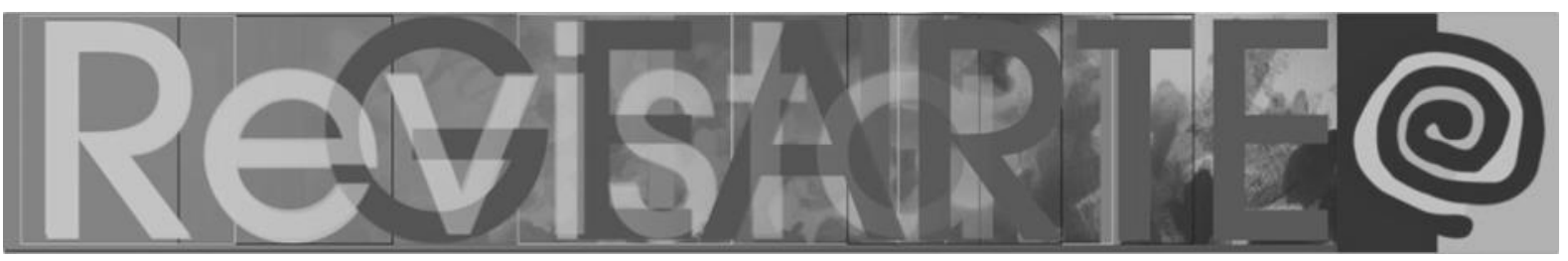

O que Bosi nomeia como "reaparição" em seus estudos e pesquisas sobre a memória está relacionado ao gesto de retomar e reabrir nos estudos de Marilena Chaui sobre o pensamento de Merleau-Ponty. Por isso, a epígrafe destaca a interpretação da filósofa brasileira sobre o pensamento do filósofo francês, no ensaio intitulado: Merleau-Ponty: o que as Artes ensinam à Filosofia, capítulo do livro Os filósofos e a Arte, organização de Rafael Haddock Lobo (2010).

A ideia, portanto, de história como possiblidade - historicidade da vida -, surgiu do e no processo de leitura dos artigos e ensaios desta edição da Revista Gearte. Além de alimentar-se das ideias de Merleau-Ponty, apropriadas por Chaui, nutre-se, muito especialmente, do pensamento de Ana Mae Barbosa pesquisadora da história da arte/educação brasileira. Sua obra é marcada por interpretações significativas sobre a nossa própria história e a influência de pensadores estrangeiros no campo da arte/educação de nosso país. É, pois, muito fecunda, basta lembrarmos algumas de suas obras e de suas ideias.

Destacamos o livro Redesenhando o Desenho: educadores, política e história (2015), pelo qual Ana Mae Barbosa recebeu o Prêmio Jabuti, em sua 58 Edição, em 2016. Enaltecemos, também, Ensino de Arte: memória e história (2009), obra que nos ajudou a nomear esta edição da Revista Gearte. Outra importante obra da autora é Tópicos Utópicos (1998). Além dessas obras, destacamos ainda a mais recente organização elaborada por Ana Mae Barbosa e Vitória Amaral, Mulheres não devem ficar em silêncio: arte, design, educação (2019). Seu estudo histórico sobre a influência do pensamento de John Dewey no campo da arte/educação de nosso país é considerado da maior importância para análise de diferentes aspectos do ensino e da aprendizagem em Arte - de modo especial das Artes e Culturas Visuais - na e para a formação humana.

Assim, a produção de seu pensamento aproxima-se do que afirma MerleauPonty (Apud CHAUI, 2010, p. 287): "[...] a grandeza de uma obra não se mede por sua eficácia, e sim por sua fecundidade". 


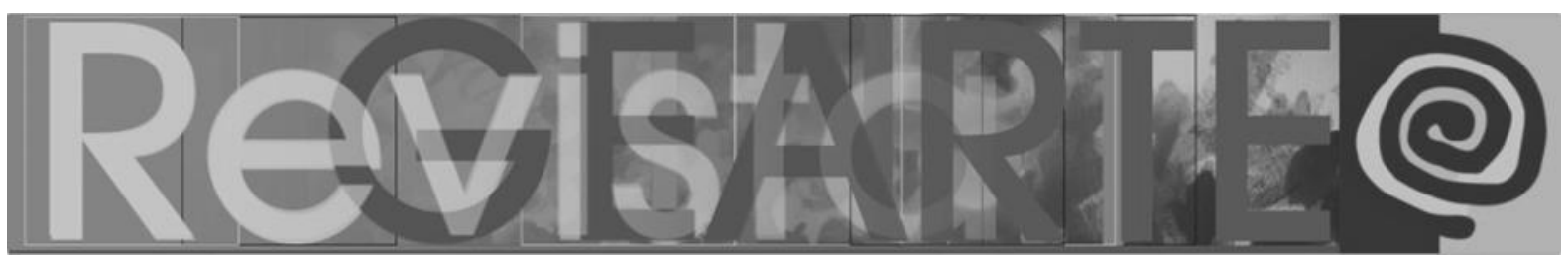

Lembramos ainda que Ana Mae Barbosa (1986) sempre nos conclamou ao estudo da história da arte/educação. De memória, muitas e muitos de nós lembramos de um significativo aspecto de seu pensamento, aqui dito como uma apropriação: "O que me assustou foi descobrir que os arte/educadores se pensam sem história, e história é importante instrumento de auto-identificação".

Há no gesto de retomar e reabrir a ideia de que as obras e os objetos de arte carecem de interpretações, pois são fazeres/pensares que exigem a produção de sentidos - nascem e se constituem como abertos.

Assim, a história da arte/educação aprende com a arte o sentido de se constituir sempre em aberto, mas não podemos deixar de destacar, nesta apresentação, as palavras de nossa grande pesquisadora da história da arte/educação:

Sem conhecer a História da sua profissão, os jovens arte/educadores acreditam no discurso de convencimento dos professores que afirmam que ela nada vale e, pior, terminam por detestar História pelo programa ao qual são submetidos, retrógados e subservientes à dominação europeia (BARBOSA, 2015, p. 33).

Apresentamos, a seguir, os artigos e ensaios que compõem este número, ressaltando que cada um chama a atenção para diferentes compreensões sobre a história da arte/educação. Convidamos arte/educadoras e arte/educadores ao gesto de retomar e reabrir.

Em Notas sobre as histórias da democratização do ensino da Arte, Ana Mae Barbosa, da Universidade de São Paulo e da Universidade Anhembi-Morumbi (São Paulo/SP, Brasil), analisa uma experiência de ensino de arte realizada em um acampamento do Movimento dos Trabalhadores Rurais Sem Terra (MST) no Rio Grande do Norte, feito em parceria com a Escolinha de Arte Newton Navarro nos anos 1990. O artigo também apresenta outra experiência de ensino de arte no Rio Grande do Norte, o curso "Pedagogia da Terra" de formação de professores do MST realizado em colaboração com a Universidade Federal do Rio Grande do Norte. A autora analisa o currículo desse curso e as relações que possuía com a 


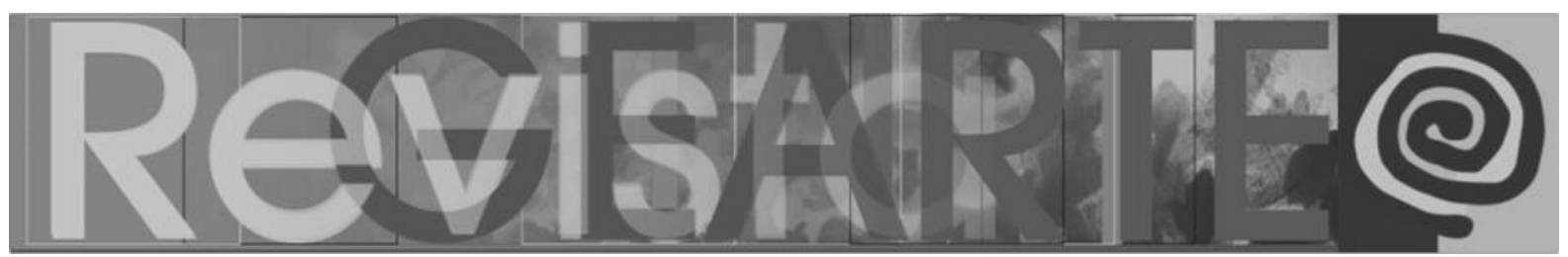

educação popular, a inspiração na obra de Paulo Freire e as concepções teóricas baseadas no ensino de arte pós-modernista.

O artigo Formación del profesorado de Primaria defendiendo la diversidad y la inclusión. Memoria de un caso de experiencia docente a través de Museari, do professor e pesquisador da Universidade de Valência, da Espanha, Ricard Huerta, analisa o trabalho realizado pelo museu online Museari, que atua no desenvolvimento de projetos voltados para os coletivos LGBT, fornecendo materiais para professores sobre a temática queer e promovendo atividades orientadas pelo respeito à diversidade e aos direitos humanos por meio da arte, da história e da educação.

Nombres retratados. Historias dibujadas transfronterizas $y$ transgeneracionales é de autoria das professoras e pesquisadoras espanholas Noemi Peña-Sánchez, da Universidad de La Laguna (Tenerife, Espanha), e Rita Noguera Ricardi, de Jugar con Arte (Madrid, Espanha). As autoras apresentam uma experiência de ensino de arte desenvolvida com estudantes da Universidade de La Laguna, na Espanha, e com crianças da organização social "Mid-Peninsula Boys \& Girls Club", localizada na Califórnia, nos Estados Unidos. O objetivo do trabalho analisado pelas pesquisadoras é promover experiências em arte que sejam culturalmente diversas, partindo do conceito de identidade.

O artigo Evoco memórias para não silenciar frente aos registros protocolares (CONFAEB de 1993), de autoria dos professores e pesquisadores Fernando Antônio Gonçalves de Azevedo, da Universidade Federal de Pernambuco (Caruaru/PE, Brasil), e Clarissa Martins de Araújo, da Universidade Federal de Pernambuco (Recife/PE, Brasil), apresenta as memórias de importantes arte/educadores que participaram do 6을 Congresso da Federação de Arte-Educadores do Brasil, ocorrido em Recife no ano de 1993. As memórias trazidas no artigo são do próprio autor Fernando de Azevedo entrelaçadas com as memórias de Ana Mae Barbosa, Vitória Amaral, Lucimar Bello, Christina Rizzi, Rejane Galvão Coutinho, Sebastião Gomes Pedrosa e Fred Nascimento. 


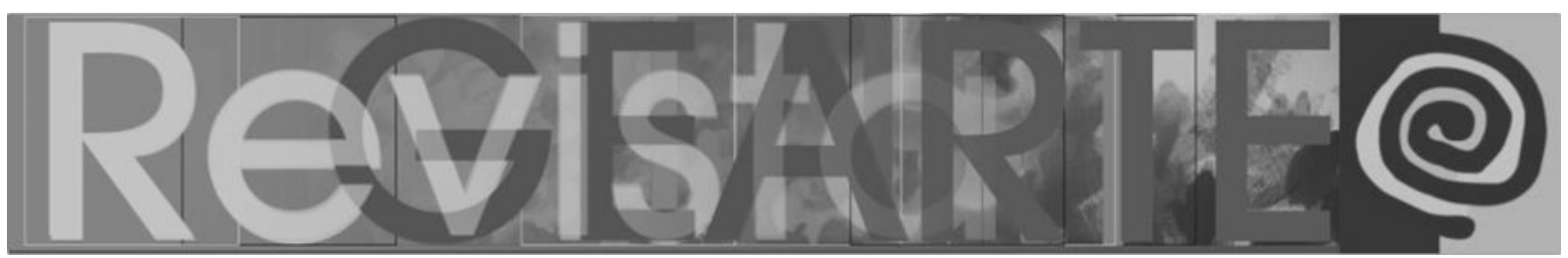

Anita, Mário e a modernidade da arte/educação brasileira, de autoria da professora e pesquisadora da Universidade Estadual Paulista Júlio de Mesquita (São Paulo/SP, Brasil), Rejane Galvão Coutinho, analisa a contribuição para a arte/educação de dois dos maiores expoentes do modernismo no Brasil: Anita Malfatti e Mário de Andrade. A autora analisa o curso de desenhos para crianças de Anita Malfatti e a coleção de desenhos infantis de Mário de Andrade, tendo como principais referências os estudos realizados por Ana Mae Barbosa e Marta Rossetti Batista.

Por meio do gesto de recordar, Um fio narrativo de histórias: professoras pioneiras das artes visuais no curso de pedagogia, construído como um misto de artigo e ensaio, por duas grandes arte/educadoras - Mirian Celeste Martins, da Universidade Presbiteriana Mackenzie (São Paulo/SP, Brasil), e Lucia Maria Salgado dos Santos Lombardi, da Universidade Federal de São Carlos (Sorocaba/SP, Brasil) - vem reafirmar o papel singular das mulheres no campo da Arte/Educação brasileira. Papel que sempre foi de luta por afirmar a Arte na formação do educador. Nesse sentido, as autoras apresentam de maneira apaixonante a trajetória arteducativa de cinco pioneiras do ensino das Artes Visuais no curso de Pedagogia. São elas: Ana Angélica Albano, Ana Luiza Ruschel Nunes, Analice Dutra Pillar, Maria Felisminda de Rezende e Fusari e Susana Rangel Vieira da Cunha. De certo modo, ao destacar Maria Fusari (Mariazinha), Mirian Celeste presta uma homenagem a sua orientadora de doutorado, que faleceu de repente às vésperas da defesa, deixando um vazio... e a responsabilidade das pioneiras aumentou. A profundidade e a beleza deste artigo/ensaio contribuem fortemente para a reflexão da história da Arte/Educação pelas trilhas dessas pioneiras.

Em \#OfuturoÉfake?Kkkkk O tempo passa, e a queda é sempre no mesmo buraco?, o próprio título do ensaio indica que sua leitura será um desafio por estarmos diante de uma sofisticada reflexão filosófica sobre o tempo/lugar em que vivemos. Tempo/lugar, em que cada vez mais, escamoteia-se as verdades - ainda que essas sejam provisórias. Vence o \# fake. Para a autora Fernanda Pereira da AZEVEDO, Fernando Antônio Gonçalves de; ALVES, Flávia Leal. Ensino de Artes Visuais: histórias e memórias. 9 Revista GEARTE, Porto Alegre, v. 7, n. 1, p. 5-13, jan./abr. 2020.

Disponível em: http://seer.ufrgs.br/gearte 


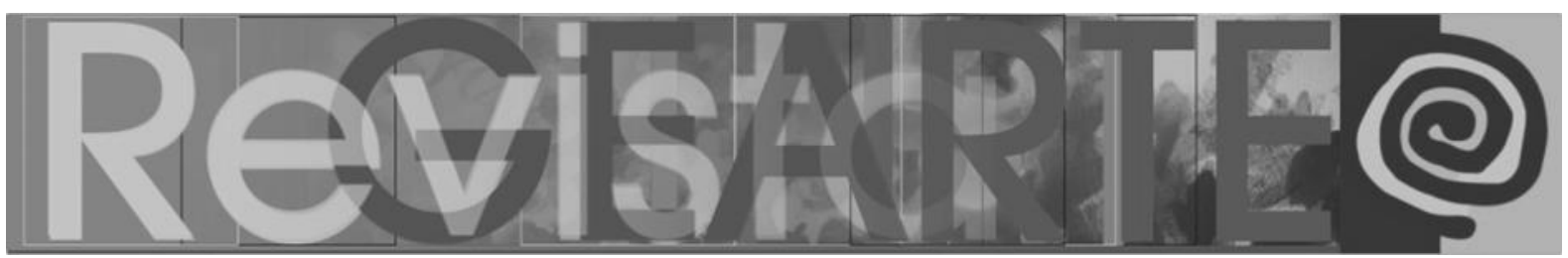

Cunha, da Universidade Federal de Goiás (Goiânia/GO, Brasil), tal marca relaciona-se com nossa herança colonialista, que produz a deformação das identidades. Além disso, a ensaísta contextualiza a década de 1990, no Brasil, como aquela marcada pelos trânsitos de um pensar analógico para um pensar digital e tal fato chega aos diversos sujeitos sociais de maneira diferente, pois esses sujeitos vão enfrentar a sonegação do conhecimento digital, assim como sofreu a sonegação de sua formação estética e artística. Apesar da complexidade do tema a autora seduz com seu ensaio por apresentar uma narrativa, que coloca em diálogo Arte, Filosofia e Ciência, de maneira refinada e cuidadosa, fato que convida leitoras e leitores a refletir sobre a complexa relação entre Arte e tecnologia, isto é, sobre e-arteducação neste tempo/lugar \# fake.

Sobre o artigo Memórias e histórias do ensino de arte em Pernambuco, no primeiro parágrafo de seu belo texto a autora Maria Betânia e Silva, da Universidade Federal de Pernambuco (Recife/PE, Brasil), cita o historiador francês, ligado a Escola dos Annales, Jacques Le Goff (2015), para enfatizar o desafio que é prever o futuro com exatidão, por isso a necessidade de interpretar o passado e não simplesmente de entender a história como uma linha tempo linear. De certo modo, os estudos e pesquisas da memória e da história vêm assumindo o caráter de incerteza a que todos os campos de conhecimento - filosofia, arte e ciência - estão sujeitados. A partir desse princípio, Maria Betânia e Silva tece as memórias e histórias do ensino de arte em Pernambuco a partir do seguinte marco: compreender o processo de inclusão da arte no currículo, com ênfase às três décadas que vieram depois da segunda metade do século XX. $O$ artigo, fruto de pesquisa, busca contribuir - com todos os sujeitos envolvidos nos processos de ensino e aprendizagem em arte - para a compreensão crítica das rupturas e permanências dos processos arteducativos contemporâneos - portanto, promove o gesto de refletir e por tal perspectiva abre muitas possibilidades de retomar e reabrir a história da Arte/Educação.

O fazer sensível de Nelma Pezzin: artista e professora, texto da arte/educadora e semioticista Moema Rebouças, da Universidade Federal do AZEVEDO, Fernando Antônio Gonçalves de; ALVES, Flávia Leal. Ensino de Artes Visuais: histórias e memórias. Revista GEARTE, Porto Alegre, v. 7, n. 1, p. 5-13, jan./abr. 2020.

Disponível em: http://seer.ufrgs.br/gearte 


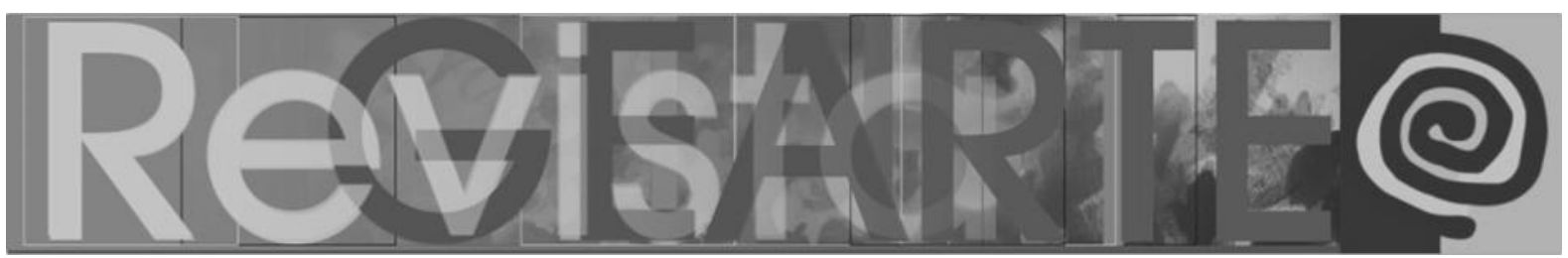

Espírito Santo (Vitória/ES, Brasil), assume um tom de homenagem aos pensares e fazeres da artista e educadora Nelma Pezzin, que por sua vez, possui também, uma formação em Semiótica. Do nosso ponto de vista, o gesto de retomar e reabrir a História da Arte/Educação torna-se enfático, neste artigo, quando a autora propõe o seguinte questionamento: como a poeticidade atua na formação das leitoras e dos leitores de Arte? E logo defende a sua hipótese: "[...] a Arte e os processos artísticos nutrem à docência...". Este é um ponto de vista de extrema importância para o campo da Arte/Educação, mais precisamente para a formação da/do arte/educadora/o, ou seja, refere-se ao gesto de arteducar pelo poético. Em muitas passagens deste artigo encontramos pontos de diálogo com a epígrafe selecionada para abrir o prefácio, por isso lembramos Marilena Chaui (2010, p. 285; grifo da autora) interpretando Merleau-Ponty: "Há advento quando há obra [há poeticidade]. $\mathrm{O}$ advento é 'promessa de acontecimentos' ". Estamos, pois, diante de um texto que possibilita muitas reflexões.

A produção de uma narrativa visual acerca do Palácio Cruz e Sousa, sede do Museu Histórico de Santa Catarina é um ensaio de Káritha Bernardo de Macedo, do Instituto Federal de Santa Catarina (Gaspar/SC, Brasil), e Mara Rúbia Sant'Anna, da Universidade do Estado de Santa Catarina (Florianópolis/SC, Brasil), em forma de relato apresentando uma experiência de narrativa verbalvisual construída sobre o Palácio Cruz e Sousa. O trabalho parte do seguinte princípio pedagógico: todo museu favorece a elaboração de narrativas visuais (e verbais). Além disso, todo museu pode propiciar o gesto de pesquisar como experiência de recriação. Fato que dialoga com a compreensão do gesto de narrar como desencadeador da reconstrução da história. O ensaio, ao apresentar a visita virtual ao Museu Histórico de Santa Catarina Palácio Cruz e Souza, abre a possibilidade para que o mesmo ocorra com outros museus. Este ensaio por seu caráter inter-linguagens favorece diversos olhares e, portanto, diferentes possibilidades de rearranjo.

O artigo Uma história imaginada: tempos de criação com 'as meninas do Renoir', de autoria de Auana Lameiras Diniz, da Universidade Estadual Paulista 


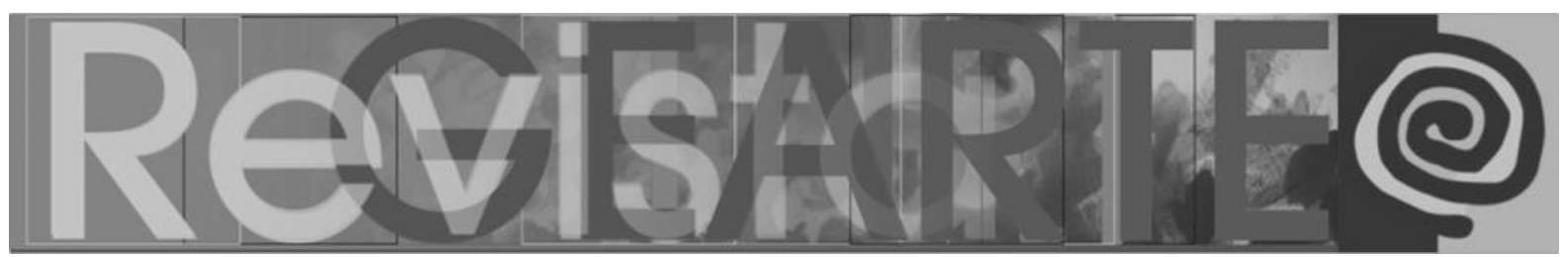

Júlio de Mesquita (São Paulo/SP, Brasil), e Rejane Galvão Coutinho, da Universidade Estadual Paulista Júlio de Mesquita (São Paulo/SP, Brasil), analisa as leituras estéticas e as recriações coproduzidas com os sujeitos da pesquisa em contato com a obra Rosa e Azul (As Meninas Cahen d'Anvers), 1881, de PierreAuguste Renoir, que fez parte da exposição de longa duração Acervo em Transformação do MASP/SP.

Olhares em dobra: relações entre arte, ecologia e saúde é o convite que o autor do ensaio visual nos propõe. Ele nos convida a vivenciar aventuras, ir além, buscar muitas relações possíveis e imaginativas entre arte, ecologia e saúde, o que significa compreender a elaboração do conhecimento como um poço sem fundo, como a produção de subjetividades. Há-braços, Água, Seca, Ondas, Vestígios, Corpo - palavras carregadas de sentidos. Para olhar em dobra, o próprio autor mergulha ousadamente no pensamento de Félix Guattari. Lembramos, pois, que este ensaio dialoga, em nossa visão, com a obra Caosmose: um novo paradigma (2012), de autoria de Guattari, em que o pensador francês defende o paradigma estético articulado ao ético, ao político, ao filosófico e ao científico. Portanto, muito próximo do que busca o olhar de Cláudio Tarouco de Azevedo, da Universidade Federal do Rio Grande (Rio Grande/RS, Brasil) e da Universidade Federal de Pelotas (Pelotas/RS, Brasil).

Queremos agradecer a todos e a todas que enviaram artigos para compor este número, aos pareceristas e à artista e professora Dra. Umbelina Barreto pela bela capa.

Mergulhemos na aventura... 


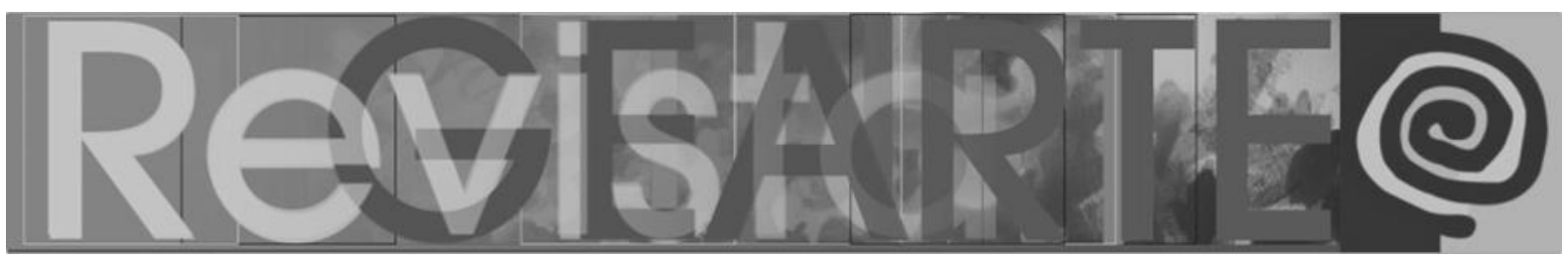

\section{Referências}

BARBOSA, Ana Mae. (Org.). História da Arte-Educação. A Experiência de Brasília. São Paulo: Max Limonad, 1986.

BARBOSA, Ana Mae. (Org.). Redesenhando o desenho: educadores, política e história. São Paulo: Cortez, 2015.

BOSI, Ecléa. Memória e Sociedade: lembranças de velhos. 3ª ed. São Paulo: Companhia das Letras, 1994.

CHAUI, Marilena. Merleau-Ponty. O que as artes ensinam à filosofia. In: HADDOCK-LOBO, Rafael (Org.). Os filósofos e a arte. Rio de Janeiro: Roco, 2010.

Dr. Fernando Antônio Gonçalves de Azevedo ${ }^{1}$ (Universidade Federal de Pernambuco - UFPE, Campus Agreste, Caruaru/PE, Brasil)

Me. Flávia Leal Alves ${ }^{2}$

(Universidade Federal do Rio Grande do Sul - UFRGS, Porto Alegre/RS, Brasil)

Organizadores do presente número

Professor do curso de Pedagogia da Universidade Federal de Pernambuco - Campus Agreste (Caruaru-PE); Licenciado em Filosofia Pura pela Universidade Católica de Pernambuco; Mestre em Artes pela ECA-USP; e Doutor em Educação pela UFPE. É membro do Grupo de Pesquisa em Educação e Arte (GEARTE).

2 Mestra em Educação pela Universidade Federal do Rio Grande do Sul (UFRGS); Graduada em História pela Universidade de São Paulo (USP), com disciplinas cursadas na Universidade ParisSorbonne (Paris IV); Graduada em Jornalismo pela Faculdade Cásper Líbero. É membro do Grupo de Pesquisa em Educação e Arte (GEARTE). É editora, gestora de projetos e autora de livros didáticos. 